\title{
Effect Of Withania Coagulans And Liraglutide On Serum Glp-1, Postprandial And Fasting Blood Glucose In Streptozotocin Induced Diabetic Rats
}

\author{
Abdul Samad, Noor Nasir Rajpoot, Hira Ayaz, Noman Sadiq \\ - - - - - - - - - - - - - - - - - - - - - - - - - - - - - -
}

ABSTRACT

Objective: To evaluate effect of Withania coagulans and liraglutide on serum Glucagon like peptide-1, Postprandial and Fasting Blood Glucose levels in streptozotocin induced diabetic rat.

Study Design and Setting: This randomize control trile was conducted at Islamic International Medical College in collaboration with National Institute of Health Islamabad.

Methodology: This randomized controlled study was performed on a total of forty male Sprague dawly rats, which were initially divided into two groups; Group A $(n=10)$ and Experimental Group $(n=30)$. Diabetes in the Experimental group B was induced by intraperitoneal administration of streptozotocin for 5 days $(30 \mathrm{mg} / \mathrm{kg} / \mathrm{day})$. Diabetes was checked in experimental group by measuring fasting blood glucose $(\mathrm{mg} / \mathrm{dl})$ on day 6 . Experimental group was further divided into Group B (Diabetic control), Group C (Withania coagulans-treated) and Group D (Liraglutide-treated). Blood sampling was done at day 30 and serum GLP-1, postprandial and fasting blood glucose levels were measured and compared in all groups.

Results: Fasting and postprandial blood glucose levels of group C and D were significantly reduced as compared to group B. Serum GLP-1 levels were significantly increased in group C and D as compared to group B.

Conclusion: Withania coagulans reduces hyperglycemia in diabetic rats through increasing GLP-1 hormone.

Keywords: Diabetes, GLP-1, Liraglutide, Withania coagulan

\section{INTRODUCTION:}

Diabetes mellitus is a metabolic disorder affecting protein, fat and carbohydrate metabolism with a global prevalence of $8.8 \%{ }^{1}$ It is characterized by relative or absolute lack of insulin leading to hyperglycemia. ${ }^{2}$ Type 2 diabetes is a chronic disease in which an individual exhibits a decrease in pancreatic beta cells function, insulin resistance and failure to inhibit postprandial glucagon secretion. ${ }^{2}$ Diabetes mellitus is a global health issue which if left untreated leads to serious morbidity and mortality. ${ }^{3}$ Studies have shown that insulinotropic function of incretin hormones especially Glucagon like Peptide-1 (GLP-1) are severely diminished in type 2 diabetes causing postprandial and fasting hyperglycemia. ${ }^{4}$ Various groups of drugs are currently in use for treating type 2 diabetes like sulphonylurea, biguanides and thiazolidinedione. ${ }^{5}$ These group of drugs have several clinical limitations, the most serious one is the eventual

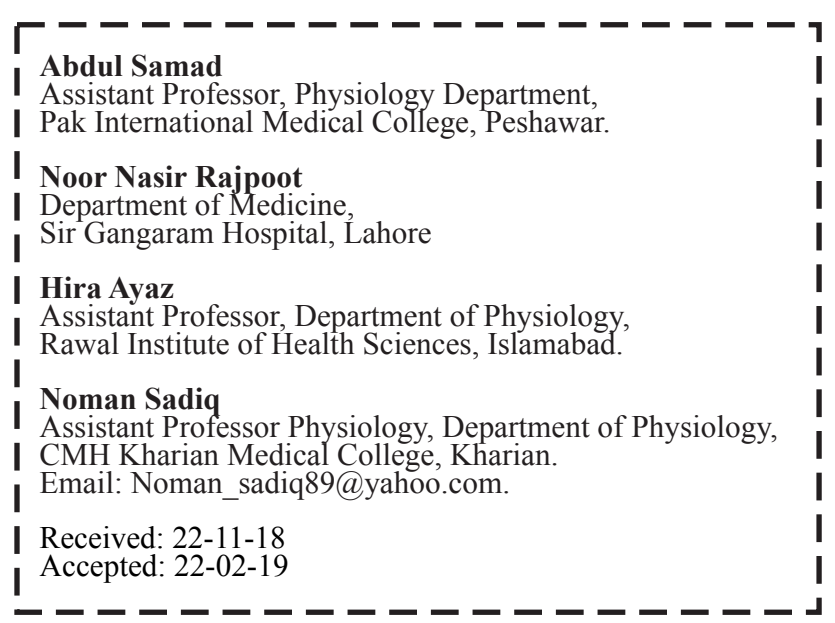

need for insulin replacement therapy. Since 2007 a new class of drug, known as GLP-1 mimetics (liraglutide and exenatide) has been in practice for treating diabetes. GLP1 mimetics targets and enhances incretin hormone (GLP-1) and have shown remarkable result in treating type 2 diabetes. ${ }^{6}$ Liraglutide, in addition to controlling hyperglycemia also upsurges glucose dependent insulin secretion (GSIS) from pancreatic beta cells. ${ }^{7}$ However high cost and parenteral administration are the two main factors which limits the use of these remarkable GLP-1 analogues. ${ }^{8}$

Due to the risk profile of antidiabetic agents, herbal medicines in are popular in practice for treating diabetes as they are well known to be free from toxic effects. ' Withania Coagulans (paneer doda) is a famous herb of family Solanaceae and is cultivated in Pakistan, Afghanistan, India and Iran. ${ }^{10-11}$ Various components of Withania Coagulans including flowers, seeds, and fruit berry extract have been studied for its several biochemical properties. ${ }^{12}$ Antidiabetic property of Withania Coagulans (aqWC) have been studied previously by using Aqueous extract of its dried fruits.

Previous Studies on animals as well as on humans have revealed that the presence of Withanolide, an active ingredient in the aqueous extract of Withania Coagulans resulted in significant improvement in blood HbA1C level. Effect of Withania Coagulans extract on reducing glucose levels were similar to the reesults produced by using biguanides and sulphonylureas. ${ }^{13}$ Moreover different studies in animal model have also shown that aqueous extract of Withania Coagulans (aqWC) significantly improves pancreatic islets cells architecture. ${ }^{14}$ However Anti-diabetic effect of aqueous extract of Withania Coagulans on incretin hormone has not 
been studied yet. Moreover studies comparing the effect of Withania Coagulans and GLP-1 mimetics on fasting and postprandial blood glucose levels are also lacking. So the current study was conducted with an aim to investigate the effect of aqueous extract of Withania Coagulans (aqWC) and Liraglutide on serum GLP-1, postprandial and fasting blood glucose levels.

\section{METHODOLOGY:}

This randomized control trial was conducted at multidisciplinary lab of Islamic International Medical College, Rawalpindi in collaboration with Animal house at National Institute of Health (NIH), Islamabad from $1^{\text {st }}$ April 2016 to $31^{\text {st }}$ March 2017 after getting approval from Ethical Review Committee of Riphah International University (RIU), Islamabad.

Male Sprague dawly rats having weight 200-300 grams were included in the study while overweight or underweight rats were excluded. A total of 40 selected adult male Sprague dawly rats were divided randomly into two groups; Group $\mathrm{A}(\mathrm{n}=10)$ and Experimental Group $(\mathrm{n}=30)$. Group A received standard diet for five days while experimental group received normal diet along with streptozotocin at a dose of $30 \mathrm{mg} / \mathrm{kg} /$ day intraperitoneally for Five days. On sixth day diabetes in experimental group was confirmed by assessing Fasting blood glucose levels $(\mathrm{mg} / \mathrm{dl})$ and its levels was compared with that of group A. The diabetic Experimental group was then randomly divided into group $\mathrm{B}$, group $\mathrm{C}$ and group $\mathrm{D}(\mathrm{n}=10)$. Group $\mathrm{B}$ received standard diet for 25 days while group $\mathrm{C}$ rats received normal diet besides aqueous extract of Withania coagulans $(1000 \mathrm{mg} / \mathrm{kg} /$ day $)$ orally mixed in drinking water. In addition to normal diet Group D rats received liraglutide drug $(0.3 \mathrm{mg} / \mathrm{kg} /$ day $)$ subcutaneously via Victoza pen for 25 days. Levels of postprandial glucose $(\mathrm{mg} / \mathrm{dl})$, fasting blood glucose $(\mathrm{mg} / \mathrm{dl})$ and serum GLP-1 level $(\mathrm{pg} / \mathrm{ml})$ was determined after 30 days of treatment by taking blood sample from group A, B, C and D.

Withania coagulans dried fruits were purchased from local market. The herb was then authenticated and identified by National Agriculture Research Center (NARC), herbarium section Islamabad. Whole fruits of W. coagulans $(1 \mathrm{~kg})$ were kept and soaked in distilled water for overnight after removal of pedicle and calyx. Water extract after the process of filtration was vaporized at temperature of 55 to $60 \mathrm{c}$ over magnetic stirrer for seven hours. As a result a semisolid material with a yield $16 \% \mathrm{wt} / \mathrm{wt}$ was obtained. This yield was further diluted with distilled water at a dose of 250 $\mathrm{mg} / \mathrm{ml}$. The diluted extract of Withania coagulans was then used for further work.

Blood sampling was done through Intracardiac sampling and $2 \mathrm{~mL}$ of blood was drawn for measuring levels of postprandial glucose, fasting blood glucose and serum GLP1 level at day 30. Rat tail vein was used for drawing blood sample at day 6 for measuring serum fasting blood glucose level.

Statistical analysis of the data was done by using SPSS version 21 and Results were documented as mean + SEM. Independent sample t-test was used for the comparison of mean among groups. A p-value of $<0.05$ was considered as statistically significant.

\section{RESULTS:}

Glucagon like Peptide-1 levels (Mean \pm SEM) in all groups (A, B, C, D) is shown in Figure -1. GLP-1 levels of group $\mathrm{B}$ rats $(931 \pm 64.12 \mathrm{pg} / \mathrm{ml})$ were significantly reduced $(\mathrm{P}<0.05)$ as compared to GLP-1 levels of group A rats $(1646$ $\pm 42.36 \mathrm{pg} / \mathrm{ml}$ ) depicting that diabetes in group B resulted in lowering of GLP-1 levels. On the other hand GLP-1 levels

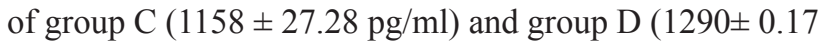
$\mathrm{pg} / \mathrm{ml})$ rats were significantly raised $(\mathrm{P}<0.05)$ as compared to the GLP-1 levels of group B $(931 \pm 67.94 \mathrm{pg} / \mathrm{ml})$ reflecting the effectiveness of GLP-1 mimetics and of withania coagulans in improving GLP-1 levels in diabetes.

Comparison of Mean \pm SEM of Fasting and Post prandial blood glucose $(\mathrm{mg} / \mathrm{dl})$ levels of the study groups is displayed in Table 1. Fasting blood glucose levels in group C rats $(98$ $\pm 1.80 \mathrm{mg} / \mathrm{dl})$ and group D rats $(102 \pm 2.04)$ were significantly lower $(\mathrm{P}<0.05)$ than group B rats $(131 \pm 3.05 \mathrm{mg} / \mathrm{dl})$. Post

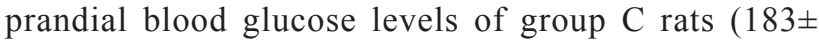
$6.30 \mathrm{mg} / \mathrm{dl})$ and Group D rats $(163 \pm 3.95 \mathrm{mg} / \mathrm{dl})$ were significantly reduced $(\mathrm{P}<0.05)$ as compare to group $\mathrm{B}(330 \pm$ $15.95 \mathrm{mg} / \mathrm{dl}$ ) rats.

\section{DISCUSSION}

Type 2 diabetes is an area of concern worldwide as it results in significant health-care cost. Medical management of type 2 diabetes comprises of oral hypoglycemic drugs (metformin,

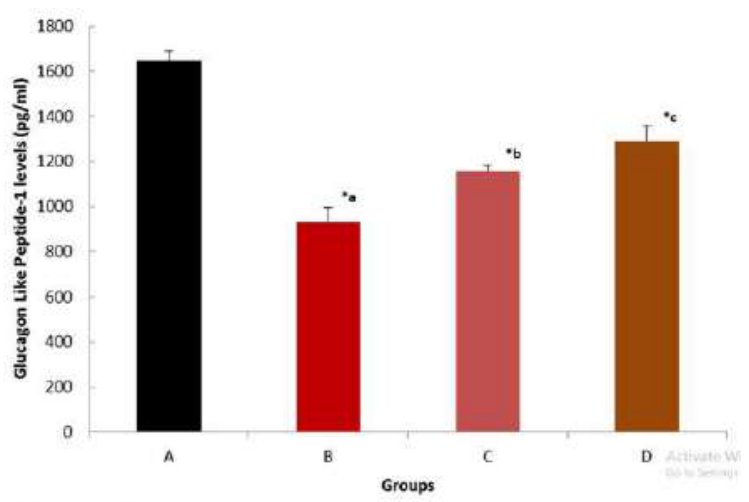

Figure 1: Comparison of Glucagon like Peptide-1(GLP-1) levels (Mean $\pm \mathrm{SEM}$ ) in various groups:

Group A: Control

Group B: Diabetic control

Group C: Withania Coagulans Treated

Group D: Liraglutide -Treated

$* \mathrm{a}=$ Group A vs B

$* b=$ Group B vs C

$* \mathrm{c}=$ Group B vs D

$*=\mathrm{P}<0.05$ is considered statistically significant. 


\begin{tabular}{|c|c|c|c|c|}
\hline Parameters & $\begin{array}{c}\text { Group A } \\
\text { (Control ) }\end{array}$ & $\begin{array}{c}\text { Group B } \\
\text { (Diabetic) }\end{array}$ & $\begin{array}{c}\text { Group C } \\
\text { (Withania } \\
\text { Coagulans treated) }\end{array}$ & $\begin{array}{c}\text { Group D } \\
\text { (Liraglutide } \\
\text { treated) }\end{array}$ \\
\hline $\begin{array}{c}\text { Fasting blood } \\
\text { glucose } \\
\text { (mg/dl) }\end{array}$ & $80 \pm 3.19$ & $131 \pm 3.05^{* \mathrm{a}}$ & $98 \pm 1.80^{* \mathrm{~b}}$ & $102 \pm 2.04^{* \mathrm{c}}$ \\
\hline $\begin{array}{c}\text { Post Prandial } \\
\text { blood glucose } \\
\text { (mg/dl) }\end{array}$ & $143 \pm 5.34$ & $330 \pm 15.95^{* \mathrm{a}}$ & $183 \pm 6.30^{* \mathrm{~b}}$ & $163 \pm 3.95^{* \mathrm{c}}$ \\
\hline
\end{tabular}

Table 1: Comparison of Mean \pm SEM of Fasting Blood Glucose $(\mathrm{mg} / \mathrm{dl})$ and Postprandial glucose $(\mathrm{mg} / \mathrm{dl})$ levels in all four Groups (A, B, C, D)

thiazolidiendiones and sulphonylurea) and parenteral drugs (Insulin and GLP-1 mimetics). In the present study antidiabetic effect of withania coagulans and GLP-1 mimetic (liraglutide) on serum GLP-1, fasting and postprandial blood glucose levels was evaluated.

Current study shows that the use of aqeous extract of Withania coagulans resulted in significant reduction in fasting and postprandial blood glucose levels which is in accordance with the work done by Jaiswal et al,.(2009) who explored the effect of aqeous extract of withania coagulans (1000 $\mathrm{mg} / \mathrm{kg}$ body wt) in streptozotocin induced diabetic rats. ${ }^{15}$ Our study also supports the finding of study done by Alam et al who orally gave 10 gram powder of withania coagulans to diabetic patients which resulted in significant reduction in their fasting and postprandial blood glucose levels. ${ }^{16}$

Hypoglycemic property of withania coagulans fruit can be explained by Boltzmann distribution law because of the substantial amount of calcium and magnesium present in the aqueous extract. Expression of insulin gene is enhanced due to the presence of significant amount of calcium ion via Calcium Responsive Element Binding protein (CREB) which is principally accountable for exocytosis of stored insulin from pancreatic beta cells. ${ }^{17}$

Findings of currents study is also in line with the study conducted by Hamaltha et al who administered aqueuous extract of withania coagulans and proved its antidiabetic effect by measuring postprandial and fasting blood glucose levels. However they administered the aqueous extract for only seven days instead of 30 days as in our case. Moreover in their study levels of serum GLP-1 was not explored. However they explored the anti-hyperlipidemic effect of withana coagulans and stated that reduction in lipid peroxidation activity and presence of antioxidants is accountable for the protection of pancreatic beta cells from oxidative damage which is the underlying cause of hyperglycemia. ${ }^{18}$

Our Study also seconds the findings obtained by Shukla et al who described the effect of aqueous extract of withania coagulans at a dose of $500 \mathrm{mg} / \mathrm{kg} / \mathrm{wt}$ on glucokinase and phosphfructokinase (carbohydrate metabolic enzymes) and concluded that withania coagulans improves blood glucose levels. ${ }^{19}$

Shimoda et al conducted a study on diabetic rats and explored the effect of GLP-1 analogue on pancreatic cell histology and GLP-1 level. The level of GLP-1 were significantly elevated after treatment with GLP-1 analogue. Findings of current study is parallel to this study results with a distinction that instead of only GLP-1 analogue we used aqueous extract of withania coagulans along with liraglutide (GLP-1 analogue) ${ }^{20}$

Datta et al., (2015) mentioned in their study that oral administration of hydroalcoholic extract of withania coagulans dried fruits to streptozotocin induced diabetic male albino rats for 4 weeks cause significant reduction in postprandial and fasting glucose levels. Withania coagulans treated group also showed the recovery of destructed pancreatic beta cells in comparison with untreated diabetic rats. They used hydroalcoholic extract of withania coagulans because in addition to hypeglycemic they also explored the antihyperlipidemic effect of withania coagulans. ${ }^{14}$

Our study results also supports the findings of study done by Lee et al (2002) who concluded that administration of maglitol to the type 2 diabetic subjects increases the post meal GLP-1 levels. ${ }^{21}$

\section{CONCLUSION}

Withania coagulans increases level of GLP-1 hormone while reducing both fasting as well as postprandial blood glucose levels. In comparison with GLP-1 mimetics the lack of adverse effects, cost effectiveness and oral mode of ingestion makes withania coagulans as a better treatment option for type 2 diabetes.

\section{REFERENCES}

1. Ogurtsova K, da Rocha Fernandes JD, Huang Y, Linnenkamp U, Guariguata L, Cho NH, Cavan D, Shaw JE, Makaroff LE. IDF Diabetes Atlas: Global estimates for the prevalence of diabetes for 2015 and 2040. Diabetes research and clinical practice. 2017 ; 128: 40-50.

2. American Diabetes Association. 2. Classification and diagnosis of diabetes: standards of medical care in diabetes-2018. Diabetes Care. 2018; 41:13-27. 
3. Krinsley JS, Maurer P, Holewinski S, Hayes R, McComsey D, Umpierrez GE, Nasraway SA. Glucose control, diabetes status, and mortality in critically ill patients: the continuum from intensive care unit admission to hospital discharge. In Mayo Clinic Proceedings 2017; 92(7):1019-29.

4. Faerch K, Torekov SS, Vistisen D, Johansen NB, Witte DR, Jonsson A, Pedersen O, Hansen T, Lauritzen T, Sandbæk A, Holst JJ. Glucagon-like peptide-1 (GLP-1) response to oral glucose is reduced in pre-diabetes, screen-detected type 2 diabetes and obesity, and influenced by sex: the ADDITIONPRO study. Diabetes. 2015: db141751.

5. Russell-Jones D, Vaag A, Schmitz O, Sethi BK, Lalic N, Antic S, Zdravkovic M, Ravn GM, Simo R. Liraglutide vs insulin glargine and placebo in combination with metformin and sulfonylurea therapy in type 2 diabetes mellitus (LEAD5 met+ SU): a randomised controlled trial. Diabetologia. 2009; 52(10): 2046-55.

6. Ahmann AJ, Capehorn M, Charpentier G, Dotta F, Henkel E, Lingvay I, Holst AG, Annett MP, Aroda VR. Efficacy and safety of once-weekly semaglutide versus exenatide ER in subjects with type 2 diabetes (SUSTAIN 3): a 56-week, openlabel, randomized clinical trial. Diabetes Care. 2018; 41(2): 258-66.

7. Kumari P, Nakata M, Zhang BY, Otgon-Uul Z, Yada T. GLP1 receptor agonist liraglutide exerts central action to induce â-cell proliferation through medulla to vagal pathway in mice. Biochemical and biophysical research communications. 2018; 499(3): 618-25.

8. Gao L, Zhao FL, Li SC. Cost-utility analysis of liraglutide versus glimepiride as add-on to metformin in type 2 diabetes patients in China. International journal of technology assessment in health care. 2012; 28(4): 436-44.

9. DeFronzo RA. Pharmacologic therapy for type 2 diabetes mellitus. Annals of internal medicine. 2000; 133(1):73-79.

10. Kumar Bharti S, Krishnan S, Kumar Sharma N, Kumar A, Prakash O, Kumar Gupta A, Kumar A. In vivo and in silico Investigation of Antidiabetic Activity of Fruit of Withania coagulans Dunal. Current hypertension reviews. 2015; 11(2): 143-58.

11. Hussain W, Badshah L, Ullah M, Ali M, Ali A, Hussain F. Quantitative study of medicinal plants used by the communities residing in Koh-e-Safaid Range, northern Pakistani-Afghan borders. Journal of ethnobiology and ethnomedicine. 2018; 14(1): 30-36.
12. Pande KH, Salve PS, Rai RK, Bali NR, Wankhede HS. Investigation and In vivo Demonstration of Synergistic Antidiabetic activity of Aqueous Extract of Aegle marmelos and Withania coagulans. Research journal of Pharmacology and Pharmacodynamics. 2014; 6(2): 101.

13. Siddiqui M, Akhtar M, Azmat J, Khalique A. A Comparative Clinical Study of Unani Formulation (Maghz Tukhm-e-Jamun wa Tukhm-e-Hayat) and Metformin in the Management of Ziabetus Shakari (Type 2 Diabetes Mellitus). Medical Journal of Islamic World Academy of Sciences. 2017; 25(2): 40-49.

14. Datta A, Bagchi C, Das S, Mitra A, De Pati A, Tripathi SK Antidiabetic and antihyperlipidemic activity of hydroalcoholic extract of Withania coagulans Dunal dried fruit in experimental rat models. Journal of Ayurveda and integrative medicine. 2013; 4(2): 99-105.

15. Jaiswal D, Rai PK, Watal G. Antidiabetic effect of Withania coagulans in experimental rats. Indian Journal of Clinical Biochemistry. 2009; 24(1): 88-93.

16. Alam A, Siddiqui MY, Hakim MH. Clinical efficacy of Withania coagulans Dunal and Trigonella foenum-graecum Linn. in Type 2 Diabetes mellitus.

17. Bharti SK et al. Antidiabetic effect of aqueous extract of Withania coagulans flower in Poloxamer-407 induced type 2 diabetic rats. Journal of Medicinal Plants Research. 2012; 6(45): 5706-13.

18. S. Hemlatha et al. Chansouria; Hypolipidemic activity of aqueous extract of Withania coagulans Dunal in albino rats, Phytotherapy Research. 2006; 20(7): 614- 17.

19. Shukla K, Dikshit P, Shukla R, Gambhir JK. The aqueous extract of Withania coagulans fruit partially reverses nicotinamide/streptozotocin-induced diabetes mellitus in rats. Journal of medicinal food. 2012; 15(8): 718-25.

20. Shimoda M, Kanda Y, Hamamoto S, Tawaramoto K, Hashiramoto M, Matsuki M, Kaku K. The human glucagonlike peptide-1 analogue liraglutide preserves pancreatic beta cells via regulation of cell kinetics and suppression of oxidative and endoplasmic reticulum stress in a mouse model of diabetes. Diabetologia. 2011; 54(5): 1098-108.

21. Lee A, et al.The effects of miglitol on glucagon-like peptide1 secretion and appetite sensations in obese type 2 diabetics. Diabetes, Obesity and Metabolism. 2002; 4(5): 329-35. 